\title{
A assistência em saúde mental no município de São Carlos/SP: considerações sobre a história e a atualidade*
}

Daniel Vannucci Dobies ${ }^{1}$

Luciana Nogueira Fioroni²

DOBIES, D.V.; FIORONI, L.N. Mental health care in the municipality of São Carlos, State of São Paulo: remarks about its history and current situation. Interface - Comunic., Saude, Educ., v.14, n.33, p.285-99, abr./jun. 2010.

Current mental health policies place importance on the network of services for attending individuals with mental disorders within the community, through providing them with social and technical support. The present study was conducted to investigate, describe and discuss mental health policy in the municipality of São Carlos, State of São Paulo. Mental health services and actions were analyzed through semistructured interviews with professionals and participant observation. The results revealed a historical delay in mental health care; services are recent and require improvements or changes; and the healthcare network is fragile. The current system is still insufficiently advanced to give support to professionals and to attend users. It was shown that collective construction of a mental health policy is needed, with more active participation by these professionals and investment in continuing education. Closer contact with the university may contribute towards this process.

Keywords: Mental health network. Mental health policy. Psychosocial care. Mental health assistance.
A atual política de saúde mental atribui importância à rede de serviços para atender às pessoas com transtorno mental junto à comunidade, respaldando-as com apoio técnico e social. Foi realizado um estudo com o objetivo de investigar, descrever e problematizar a política de saúde mental no município de São Carlos/SP, a partir dos serviços e ações em saúde mental, utilizando entrevistas semiestruturadas com profissionais e observação participante. Observou-se um atraso histórico no cuidado com a saúde mental; os serviços são recentes, demandando aprimoramentos ou transformações, e a rede de saúde exibe fragilidades. $\mathrm{O}$ atual arranjo apresenta avanços ainda insuficientes para dar suporte aos profissionais e atender os usuários. Mostra-se necessária a construção coletiva de uma política de saúde mental, com participação mais ativa dos profissionais, e o investimento em educação permanente. A aproximação com a universidade poderá contribuir nesse processo.

Palavras-chave: Rede de saúde mental. Política de saúde mental. Atenção psicossocial. Assistência em saúde mental.
"Texto inédito, resultado do trabalho de conclusão do Programa de Residência Multiprofissional em Saúde da Família e Comunidade da Universidade Federal de São Carlos. Projeto aprovado pelo Comitê de Ética em Pesquisa em Seres Humanos da Universidade Federal de São Carlos - CAAE 4012.0.000.135-07 Parecer n.136/2008. ${ }^{1}$ Centro de Atenção Psicossocial Álcool e Drogas Independência, Serviço de Saúde Dr. Cândido Ferreira, Campinas, SP. Rua das Violetas, 362, bl. 15, apto. 24, Vila Mimosa, Campinas, SP, Brasil. 13.050-063. dvdob@yahoo.com.br ${ }^{2}$ Departamento de Psicologia, Universidade Federal de São Carlos. 


\section{Considerações sobre a história e a situação atual da saúde mental no Brasil}

O contexto sócio-histórico tem papel definidor na construção da relação da sociedade com as pessoas em sofrimento mental, produzindo diferenças ao longo do tempo e em diferentes sociedades. Foucault (1984) destaca a cíclica alimentação entre saber e poder, produzidos historicamente e dentro de um contexto sociocultural, como determinante das práticas sociais, particularmente dirigidas às pessoas em sofrimento mental.

Entre os séculos XVIII e XX, o modelo hegemônico produziu a exclusão da loucura, enclasurando-a em manicômios. Após a Segunda Guerra Mundial, conforme Castel (1978), houve, no mundo ocidental, um movimento de reforma dos hospitais psiquiátricos, com: melhoria da infraestrutura hospitalar, política de 'porta aberta' para atenuar a ruptura hospital-mundo exterior, trabalho em equipe e investimento na formação dos profissionais.

As práticas hegemônicas passaram a ser contestadas, emergindo os movimentos de Comunidade Terapêutica e de Psiquiatria Comunitária e Preventiva que, apesar das críticas à assistência hospitalar e das novas propostas de intervenção, mantinham o hospital como referência para o tratamento. Cooper (1989), ao considerar a complexidade das relações familiares e sociais, as quais podem levar ao adoecimento psíquico, aponta a importância de investir cada vez mais em intervenções inseridas na comunidade, fora do hospital psiquiátrico.

Foi na Itália que Basaglia (1985) realizou mudanças estruturais no tratamento, considerando a necessidade de construir uma nova relação da sociedade com a pessoa em sofrimento mental, que privilegiasse a vida comunitária e a liberdade, em contraposição à contenção e a exclusão vigentes. Entendia ser contraditória a busca da cura pela tutela em instituições fechadas, pois a cura pressupõe a tendência à expansão espontânea e pessoal do sujeito. Diante disso, propõe a desinstitucionalização com o fechamento do manicômio e sua substituição por serviços inseridos nos territórios. Esse autor destaca quanto essa mudança exige consciência política dos profissionais, perante a própria atuação, pois as intervenções técnicas também definem o lugar da loucura e do sujeito acometido.

O Brasil também apresenta uma história de asilamento e tratamento moral, como apontam diversos autores, entre eles Amarante $(2007,1994)$ e Resende (1997). Tenório (2002) afirma que, na década de 1970, os pressupostos do asilo e da psiquiatria não eram criticados, questionavam-se somente seus excessos ou desvios. Foi na década seguinte, num período efervescente de mudanças na saúde e de participação popular, que o movimento ganhou consistência, propondo novas formas de cuidado ao invés de aperfeiçoar o modelo vigente. Surgem experiências institucionais bem-sucedidas numa nova perspectiva de cuidado, tais como os Núcleos de Apoio Psicossocial (NAPS) em Santos/SP e o Centro de Atenção Psicossocial (CAPS) em São Paulo/SP.

Na década de 1990, o processo da reforma psiquiátrica brasileira amadureceu e se consolidou com a regulamentação e o aumento de serviços alternativos ao hospital psiquiátrico (Tenório, 2002). Tornou-se evidente a necessidade da organização em rede desses serviços, para que o processo atingisse seus objetivos (Amarante, 2007). Essa nova assistência valoriza a permanência da pessoa, em sofrimento mental, na comunidade. Como destacam Lancetti e Amarante (2008), o bairro, a família, a comunidade e as unidades de saúde encravadas no território são identificados como locais privilegiados para esse tratamento. Assim, há uma aproximação entre as Reformas Psiquiátrica e Sanitária, por ambas apresentarem mudança de paradigma, enfatizando as intervenções dentro do território e o vínculo como mediador do cuidado (Nunes, Jucá, Valentim, 2007).

Diversas experiências, com base nos princípios da atenção psicossocial, ocorreram pelo país e algumas delas foram publicadas: Campinas/SP (Merhy, Amaral, 2007; Harari, Valentini, 2001), Belo Horizonte/MG (Brasil, 2006b), Quixadá/CE (Brasil, 2006a; Lancetti, 2001), São Paulo/SP, Camaragibe/ $\mathrm{PE}$, Cabo de Santo Agostinho/PE, Sobral/CE e Vale do Jequitinhonha/MG (Lancetti, 2001). Estas experiências, dentro de suas peculiaridades, mostram que é fundamental a criação de serviços substitutivos, com sustentação em rede, para manter o usuário na comunidade. Dessa forma, elas se afinam com as recomendações da Organização Mundial de Saúde (OMS, 2001) e do Ministério da Saúde (Brasil, 2009a, 2009b). 


\section{Trabalho de campo em São Carlos}

${ }^{3}$ Localizado a cerca de 230 km da capital, na região central do estado de São Paulo. Apresenta uma população de 213.314 habitantes (São Carlos, 2007).

${ }^{4}$ O Programa envolve dez profissões: educação física, enfermagem, farmácia, fisioterapia, fonoaudiologia, nutrição, odontologia, psicologia, serviço social e terapia ocupacional. Ele faz parte da Rede Escola de

Cuidado, produto da parceria entre a

Prefeitura Municipal e a Universidade Federal de São Carlos (UFSCar).

${ }^{5}$ Esse objetivo será discutido mais detalhadamente em outra publicação.
O município de São Carlos/SP³, segundo parâmetros populacionais, não conta com todos os serviços de saúde mental recomendados pelo Ministério da Saúde (Brasil, 2009b). Para um município com a sua dimensão populacional, são recomendados: CAPS II, CAPS III, CAPSad, CAPSi, e rede básica com ações de saúde mental e capacitação do SAMU. Entretanto, o município oferece ações de saúde mental nas atenções básica e especializada, que serão apresentadas e discutidas ao longo do estudo.

De modo geral, há um processo de mudança na área da saúde desse município nos últimos anos, sobretudo, pelo maior investimento na Atenção Básica, atingindo, de alguma forma, a assistência em saúde mental. Dentre as novas propostas, encontra-se a Residência Multiprofissional em Saúde da Família e Comunidade (RMSFC) ${ }^{4}$, que inseriu profissionais de saúde mental nas Unidades de Saúde da Família (USF), denotando certa intencionalidade no fortalecimento da saúde mental na Atenção Básica.

Este estudo foi desenvolvido no Programa da RMSFC, com objetivo geral de investigar, descrever e problematizar a política de saúde mental no município de São Carlos, com base nos serviços e ações em saúde mental. Especificamente, atentando para três pontos: como os serviços de saúde estão interligados, no que diz respeito à saúde mental; o modo como os usuários são atendidos pelos serviços que prestam assistência à saúde mental ${ }^{5}$; e quais são as implicações de tal estrutura na atribuição de cada serviço e no trabalho dos profissionais.

Diante dos objetivos propostos, foi realizada uma pesquisa de campo por meio de entrevistas semiestruturadas. Num primeiro momento, realizou-se um levantamento dos serviços que prestam assistência em saúde mental, ligados à Secretaria Municipal de Saúde. Na sequência, foi solicitada entrevista aos gestores dos serviços especializados em saúde mental e a um profissional de cada serviço. Alguns serviços só dispunham de um profissional de saúde mental. No caso de serviços com mais de um, a escolha foi aleatória. Nas entrevistas, abordaram-se: dados pessoais; formação e atuação profissional; avaliação sobre o próprio trabalho, a instituição e a rede de serviços. Elas ocorreram entre abril e setembro de 2008.

Ao considerar a abordagem etnográfica e a inserção de um dos pesquisadores na rede de serviços de saúde, a observação participante foi definida como instrumento de investigação. Isso permitiu o acompanhamento da rotina dos serviços e produziu subsídios para uma leitura mais dinâmica e legítima da lógica de atendimento. Este recurso esteve presente no cotidiano, durante o período da Residência, conforme a necessidade de contato com outros serviços e/ou circulação por eles.

Os dados foram analisados a partir da dimensão institucional e política dos serviços, com base no referencial teórico das Reformas Psiquiátrica e Sanitária. A análise do conteúdo das entrevistas seguiu as etapas propostas por Minayo (2000). Assim, foram feitos apontamentos iniciais, estabelecendo relações entre questões teóricas e dados empíricos. Em seguida, destacaram-se os conteúdos reveladores dos possíveis núcleos de sentido. E, por fim, foram realizadas a definição e a descrição dos núcleos de sentido.

\section{Os profissionais entrevistados}

A descrição dos profissionais é importante por permitir a contextualização das suas falas e o conhecimento mais detalhado de quem compõe os serviços do município. 
Quadro 1. Características dos profissionais entrevistados.

\begin{tabular}{|c|c|c|c|c|c|c|c|}
\hline & Idade & Sexo & $\begin{array}{c}\text { Instituição de } \\
\text { graduação }\end{array}$ & Titulação* & $\begin{array}{c}\text { Nível de atenção } \\
\text { do serviço }\end{array}$ & $\begin{array}{c}\text { Tempo de } \\
\text { formação }\end{array}$ & $\begin{array}{c}\text { Tempo de } \\
\text { serviço }\end{array}$ \\
\hline $\mathbf{1}$ & 51 & F & Privada & Mes; 2 Esp & especializada & 30 anos & 8 anos \\
\hline $\mathbf{2}$ & 34 & F & Privada & Esp; Form & especializada & 12 anos & 8 anos \\
\hline $\mathbf{3}$ & 48 & F & Privada & Esp & especializada & 27 anos & 8 anos \\
\hline $\mathbf{4}$ & 38 & F & Pública & Esp; Form (a) & especializada & 8 anos & 8 anos \\
\hline $\mathbf{5}$ & 28 & F & Privada & Esp & especializada & 6 anos & 4 anos \\
\hline $\mathbf{6}$ & 50 & M & Pública & Res; Form (i) & especializada & 26 anos & 8 anos \\
\hline $\mathbf{7}$ & 28 & F & Privada & Esp; Esp (a) & especializada & 4 anos & 2 anos \\
\hline $\mathbf{8}$ & 43 & F & Pública & Apr; Mes; Dou; Form & especializada & 20 anos & 7 meses \\
\hline $\mathbf{9}$ & 36 & F & Privada & Res & básica & 9 anos & 4 anos \\
\hline $\mathbf{1 0}$ & 44 & M & Pública & Res; Mes & básica & 17 anos & 1 ano \\
\hline $\mathbf{1 1}$ & 37 & F & Privada & Res; Form (a) & básica & 16 anos & 1,5 anos \\
\hline 12 & 32 & F & Pública & Esp & básica & 7 anos & 2 meses \\
\hline 13 & 41 & F & Privada & 2 Esp & especializada & 17 anos & 2 anos \\
\hline $\mathbf{1 4}$ & 40 & F & Pública & 4 Esp; Mes; Form; Dou (a) & especializada & 19 anos & 8 anos \\
\hline 15 & 39 & F & Privada & 2 Esp & especializada & 19 anos & 1 ano \\
\hline
\end{tabular}

*Mestrado (Mes); Especialização (Esp); Formação (Form); Residência (Res); Aprimoramento (Apr); Doutorado (Dou). A abreviação "(a)" significa que se encontra em andamento e "(i)" que ficou inacabado.

Participaram do estudo 15 profissionais: 13 mulheres e dois homens; dois eram coordenadores de serviço. Idade média de 39,3 anos. Em relação à formação, foram: nove psicólogos, quatro psiquiatras e dois terapeutas ocupacionais. Nove dos entrevistados fizeram graduação em instituições privadas e outros seis, em universidades públicas. O tempo médio de formado foi de 15,8 anos, com aproximadamente dois cursos de pós-graduação por profissional, envolvendo "lato sensu" e "stricto sensu". Quanto ao nível de atenção dos serviços, 11 se encontravam trabalhando na Atenção Especializada, e quatro, na Atenção Básica. Em relação ao tempo de serviço, a média foi de 4,3 anos, em um intervalo de dois meses a oito anos.

Boa parte dos trabalhadores de saúde mental se encontra com, aproximadamente, o mesmo tempo de serviço, pois houve maior incorporação desses profissionais por volta do ano 2000. Os psiquiatras, em geral, estão há menos tempo nos serviços, devido a maior rotatividade, dificultando a organização da rede e articulação entre profissionais, além de aumentar as reclamações dos usuários. Existem até profissionais que explicam a razão dessa rotatividade:

\footnotetext{
"Você trabalha num lugar desagradável, esteticamente falando, remuneração baixa, a demanda é altíssima, você não tem equipe. Às vezes, a pessoa até entra, mas ela não fica. Tem a pressão que eu entendo desfavorável, que é da resolutividade". (P9)
}

Entretanto, a rotatividade não se limita aos psiquiatras. Ao longo do período pesquisado, várias mudanças ocorreram, tais como: saída da psicóloga do Hospital-Escola Municipal; expansão da proposta de matriciamento pelos psiquiatras, que diminuiu o tempo deles nos Núcleos Integrados de Saúde (NIS); saída da coordenadora do Centro de Atenção Psicossocial - álcool e/ou outras drogas (CAPSad), que foi para um NIS; contratação de nova psicóloga para o CAPSad; saída do coordenador de saúde mental, após cerca de um ano de trabalho, sem motivo explicitado ou comunicado aos serviços de saúde. Evidentemente, cada situação apresenta uma particularidade, mas não se pode desconsiderar a alta frequência de mudanças nos recursos humanos. 
Quase todos os profissionais relatam trabalhos em lugares diversificados e/ou desenvolvimento de diferentes ações dentro da própria categoria profissional. Foram poucos que direcionaram sua formação e permaneceram, ao longo da carreira, nos serviços relacionados a esta escolha. As razões são muitas, entre elas: mercado de trabalho, oportunidade de emprego, tentativa de melhorar de vida e necessidade de se sustentar. Isso mostra quanto os profissionais têm encontrado dificuldades para se realizarem, seja no aspecto financeiro, de formação e/ou de satisfação pessoal.

No que diz respeito à formação, ressalta-se o fato de alguns entenderem a formação básica consistente como imprescindível para encarar as frequentes mudanças nos modelos de assistência, bem como aquelas que são intrínsecas à natureza desse trabalho:

\footnotetext{
“O campo da psiquiatria e da saúde mental é muito dinâmico. Ele muda a cada momento. O SUS e a saúde pública são coisas em constante mutação. Então, você tem que formar pessoas para poder se comportar dentro de um campo em mutação frequente, com novos saberes chegando a cada momento. [...] Se a formação básica for bem feita, você está pronto para entrar e participar das mutações. Isso evita com que você seja formado em determinada técnica ou conduta e persevere nisso, enquanto o mundo está rodando". (P6)
}

Esse processo de transformação ocorre até mesmo nos lugares onde há maior clareza dos objetivos a serem atingidos, os quais exigem um planejamento estratégico para enfrentar prováveis crises, como afirmam Koda e Fernandes (2007). Elas explicam que as mudanças não se dão linearmente e estão sujeitas aos contratempos, tais como: situações novas com os usuários no novo contexto e mudanças de gestão.

Como foi dito anteriormente, poucos entrevistados direcionaram sua formação para o trabalho atual. Alguns nem tiveram oportunidade de adquirir o instrumental necessário para a atual função. Apontaram que não há preparo para as equipes e/ou profissionais iniciarem a assistência e nem mesmo educação permanente. Muitos, então, se capacitaram e se capacitam individualmente e simultaneamente à execução do trabalho.

A decisão por trabalhar no serviço em que estão inseridos apresenta particularidades e diversidades, correspondendo ao dado encontrado por Spink et al. (2007) a respeito do perfil de psicólogos brasileiros que atuam no SUS. Esses autores apontam que há ingresso por: vocação, paixão, desejo de ajudar as pessoas de baixa renda, projeto político pessoal e opção em um mercado de trabalho sabidamente precário.

Entretanto, a garantia de segurança financeira, proporcionada pelo serviço público, foi recorrente nos relatos. Fator, este, bastante influente na decisão por trabalhar no serviço público, como se observa neste trecho:

\footnotetext{
"O serviço público é muito claro, é onde você tem garantias de trabalho, ganho, aposentadoria. Viver de atendimento particular é muito perigoso, ousado. Pouca gente pode viver disso". (P6)
}

Esses são alguns aspectos dos profissionais entrevistados. Ressalva-se, entretanto, a existência de residentes multiprofissionais alocados nas USFs, não incluídos por não se enquadrarem no perfil focado neste estudo. Os residentes têm vinculação diferenciada, estando nos serviços em processo de aprendizagem.

\section{Fragmentos históricos da assistência em saúde mental no município}

Antes de descrever a configuração do atual arranjo da assistência em saúde mental do município, será retomada a sua história, segundo relatos dos profissionais entrevistados.

Até o ano 2000, os usuários com necessidade de cuidados em saúde mental, muitas vezes, eram levados para os municípios vizinhos que mantinham hospitais psiquiátricos, sobretudo Araraquara/SP distante aproximadamente quarenta km de São Carlos/SP. A "exportação" dessas pessoas ocorria em 
razão de o município não contar com profissionais suficientes e nem com serviços estruturados para oferecer essa assistência.
"Antes de 2000, não tinha isso. Aqui não havia hospital psiquiátrico [...]. O hospital mais próximo é em Araraquara. Até 2000, não havia rede, não havia nada, não tinha psiquiatra. Tinham neurologistas que se empenhavam em fazer alguma coisa, num raciocínio neurológico. Tinham uns poucos psiquiatras [cita cinco nomes, incluindo o serviço privado]". (P6)

Em outro relato, é acrescentado que, até 2000, só havia uma psicóloga no serviço público, atendendo à população com HIV.

Em 2000, o município incorporou muitos profissionais de saúde mental. Num primeiro momento, aproximadamente um ano e meio, houve uma concentração no Centro de Especialidades (CEME), formando um grande ambulatório de saúde mental, com psiquiatra, psicólogo, neurologista, terapeuta ocupacional e fonoaudiólogo. Aos poucos, cada profissional direcionou o atendimento a determinada população e houve mudanças de gestão. Elegeu-se um coordenador de saúde mental e começou um processo de descentralização, com: a criação do ambulatório para o atendimento infantil (fevereiro/ 2002), inauguração do CAPS (março/2002), regionalização do atendimento ambulatorial de psicólogos e psiquiatras (outubro/2002), e inserção de profissionais de saúde mental em outros ambulatórios especializados (DST/Aids e Oncológico).

Dentre essas mudanças, a regionalização foi a mais complicada. Em alguns relatos, ela foi descrita como "agressiva". Os profissionais de saúde mental assimilaram mal a forma como transcorreu o processo, queixando-se de não participarem efetivamente no seu decorrer, classificando-o como uma imposição da gestão. Além disso, a proposta inicial, não concretizada, era de que cada uma das cinco Regionais de Saúde do município contasse com uma equipe no NIS, com: um psicólogo para atender crianças, outro para atender adultos, dois terapeutas ocupacionais, educador físico, entre outros. Um profissional entende que:

"A saúde mental está totalmente pulverizada aqui em São Carlos. [...] Mudou a administração, a filosofia de trabalho e, hoje, a gente não tem com quem conversar". (P1)

A regionalização da assistência à saúde, respaldada pelas diretrizes do SUS, foi iniciada com a saúde mental e houve resistência tanto dos profissionais que estavam sendo regionalizados como daqueles que os receberam.

Enquanto isso, a inserção, em outros ambulatórios, foi mais tranquila, na medida em que eles mesmos foram se inserindo e manifestavam esse desejo. A criação do ambulatório infantil ficou facilitada pela mesma razão. Entretanto, neste caso, houve complicações: ausência, por muitos anos, de um psiquiatra trabalhando em conjunto com as psicólogas e de um neurologista próximo ao ambulatório; e permanência, por cerca de seis anos, deste ambulatório dentro da instituição do município que trabalha com adolescentes infratores.

O CAPS, por sua vez, foi criado em decorrência de uma série de ações. A partir de um projeto de extensão da UFSCar (com parceria entre os Departamentos de Terapia Ocupacional e Psicologia), iniciou-se um trabalho com usuários na sala de espera do "corredor de saúde mental" do CEME, que destinava-se a proporcionar educação em saúde e outras atividades alternativas ao modelo tradicional. Concomitantemente, criou-se o Fórum de Saúde Mental, que manifestava a insatisfação com a forma de atendimento vigente no município. Foi formulada, então, uma proposta de instalação de serviços de saúde mental, seguindo o modelo de Santos/SP, com a implantação de um CAPS/NAPS em cada regional de saúde para atender todas as pessoas que demandassem atenção em saúde mental. Tal plano foi revisto, considerando a III Conferência Nacional de Saúde Mental e a portaria de regulamentação dos CAPS. Assim, houve uma opção em seguir as diretrizes desta publicação para viabilizar a implantação de um CAPS II, que se deu em março de 2002. E, simultaneamente, reforçar, nas Regionais, o cuidado de saúde mental, descentralizando os atendimentos ambulatoriais. 
Implantado em 2006, o CAPSad até 18 anos tem uma história ligada a outros setores. Com base em discussões sobre dificuldades na atenção de adolescentes em uso problemático de álcool e/ou drogas no Conselho de Infância e Juventude, foi definido o projeto do CAPSad. Assim, este foi criado pela Rede da Criança e do Adolescente do município, aproveitando as recomendações do Estatuto da Criança e do Adolescente (ECA). A preocupação era evitar as internações em instituições não governamentais - promover a desospitalização -, além de provocar a Saúde a assumir o cuidado dessa população.

Diferentemente, o município não sofreu a mesma pressão quanto à assistência à população adulta que apresenta uso problemático de álcool e/ou drogas. Esse cuidado é limitado ao atendimento ambulatorial nas Regionais e internação no hospital psiquiátrico de referência, embora profissionais e coordenadores assumam não ser esta a terapêutica mais adequada. Existem movimentações para a criação do CAPSad adulto, ou para que o CAPSad atual amplie a faixa etária atendida.

A história do município é marcada pela ausência de recursos e investimentos. A inexistência de serviços estruturados e profissionais até 2000 , o espaço físico inadequado, a falta de profissionais para regionalização da assistência e ausência de estrutura adequada para atender determinadas populações, entre outros, prejudicaram a situação atual.

\section{A situação atual da assistência em saúde mental no município}

A assistência em saúde mental é prestada: no CAPS II; no CAPSad até 18 anos; no Ambulatório de Psiquiatria e Psicologia Infantil; e na Unidade SaúdeEscola da UFSCar. Na Atenção Básica, existem: atendimentos de psiquiatras e psicólogos nos cinco NIS do município; apoio matricial dos residentes multiprofissionais, em 14 das 15 equipes de Saúde da Família, e dos psiquiatras, em pelo menos metade dessas equipes. Há ainda profissionais de saúde mental

${ }^{6}$ A ele está vinculado o Programa de Atendimento à Vítima de Abuso Sexual (PAVAS), que atende mulheres acima de 18 anos, incluindo casos de violência doméstica; e também o Ambulatório de Sexualidade Feminina para tratamento das disfunções sexuais. inseridos no Hospital-Escola Municipal, no Ambulatório Oncológico e no Ambulatório de DST/AIDS ${ }^{6}$. Serviços ligados à Secretaria de Cidadania, às universidades e às organizações não governamentais também prestam assistência em saúde mental. O hospital psiquiátrico de referência continua sendo o de Araraquara/SP.

Quase todos os serviços de saúde, descritos acima, atendem à demanda espontânea, valendo-se do recurso do acolhimento ou de entrevistas de triagem, sem a exigência de encaminhamento. A exceção é o hospital psiquiátrico, que realiza internações via regulação.

Apesar de tal facilidade de acesso, os profissionais entrevistados, repetidamente, apontam deficiências de articulação:

\footnotetext{
"Não tenho tido respaldo, devolutiva, se eles têm acolhido ou não. A única notícia foi a de adolescente que encaminhei e soube que conseguiu marcar psicóloga. Algumas pessoas que encaminhei não voltaram. Não sei se foram ao serviço ou se desistiram. [...] [Por outro lado] Não consigo dar devolutiva para os serviços que encaminham para mim". (P12)
}

"Não tenho articulação com outros serviços, no sentido de que o usuário possa ir e voltar conforme a sua necessidade". (P10)

Queixas com relação ao isolamento do CAPS são frequentes, configurando-se numa barreira para o trabalho em conjunto. Por outro lado, profissionais deste 
serviço apontam dificuldades de contato com os demais, especialmente no processo de saída do usuário, com inserção na Atenção Básica:

\begin{abstract}
"As enfermeiras estão com outra postura, fazendo acolhimento. Isso ajuda muito. [...] Antes não conversava com ninguém e a escuta do balcão é muito diferente. Às vezes, não é um caso severo, mas que não pode ficar solto. Tem vezes que eu ligo e aviso que o usuário está indo e precisa dar uma olhada. [...] A gente já tentou mandar a referência para o paciente ir lá sozinho, mas ele volta. Hoje eu ligo e falo com as administradoras regionais para discutir o agendamento, se precisa manter o usuário no CAPS até o dia da consulta na UBS ou se precisa fazer busca ativa dos usuários do CAPS. Até a equipe questiona, dizendo que isso não é o meu papel, que não devo fazer isso". (P14)
\end{abstract}

Nesta fala, o acolhimento é apontado como um recurso para melhorar a articulação entre serviços e o acesso aos usuários. No entanto, explicita a inadequação em destinar ao usuário a função de construir a sua própria rede, sem que haja uma estrutura organizada para tal e com dificuldades de contato até mesmo entre profissionais. Percebe-se, também, o esforço individual do profissional para dar continuidade ao cuidado em conjunto com outros serviços, reafirmando a desarticulação e gerando sobrecarga de trabalho.

Apesar dos limites inerentes, ao se atribuir a responsabilidade por construir a rede a um profissional individualmente, é válido considerar o que Mattos (2007) aponta sobre essa discussão, na perspectiva da integralidade. Ele enfatiza a responsabilidade de todo profissional, em qualquer serviço, inserir o usuário na rede de cuidados. Responsabilidade aumentada diante de uma atenção à saúde que não funciona idealmente, na qual se poderia contar com estruturas de hierarquização e regionalização bem consolidadas.

A falta de contato entre os serviços fica mais evidente, na medida em que os profissionais pouco se conhecem, e alguns desconhecem os serviços para onde encaminham os usuários para dar continuidade à terapêutica adequada. Nem mesmo as instituições especializadas são conhecidas por todos os profissionais, e tal desconhecimento não se restringe aos recém-contratados.

No limite extremo da desarticulação, existe a percepção de que o município tem uma história tão complicada a ponto de não ser possível dizer que há serviços de saúde mental, mas somente profissionais que atendem:

"A história em São Carlos é problemática, pois nunca teve um serviço de saúde mental. Serviço entendido como uma instituição, com mentalidade de trabalho em comum. $\mathrm{Na}$ verdade, em São Carlos, existem pessoas atendendo, mas não há um conjunto de serviços organizados". (P10)

Esta desarticulação produz prejuízos, entre eles: 1) a demora para que o usuário, egresso do CAPS, continue o seu tratamento com psiquiatra na Atenção Básica, pois, burocraticamente, exige-se que o usuário passe primeiro pelo clínico antes do encaminhamento ao psiquiatra; 2) a desconfiguração do CAPS, que mantém usuários com transtorno leve, moderado ou aqueles que já não têm indicação para cuidado intensivo, por estes não conseguirem seguimento na Atenção Básica, nem em outros setores; 3) o isolamento e medicalização da assistência na Atenção Básica.

Os profissionais alocados na Atenção Básica descrevem uma assistência ambulatorial restrita ao consultório. Queixam-se de uma herança, consequente a um longo período em que os usuários foram acostumados a pedir e trocar suas receitas de medicamentos, sem passar por nenhum tipo de reavaliação. Esses trabalhadores afirmam que se sentem envolvidos por uma lógica de "produção de doença", dado o grande volume de receitas solicitadas, acrescidas de cartas para benefício e aposentadoria. No limite, chegou a ocorrer o fechamento de agenda para novos casos, como forma de buscar atender, resolutivamente, aos casos, há muitos anos, sem resolutividade.

Essa situação é bem semelhante à descrita por Bezerra Júnior (1997) sobre o risco que se corre na atenção ambulatorial: 
Na verdade, a maioria dos psiquiatras não atende, despacha. Não medica, mas repete receitas. A falta de tempo impede que se chegue a um diagnóstico de confiança, as marcações de trinta em trinta dias ou mais impossibilita uma evolução do caso, e o círculo vicioso vai cronificando médico e paciente neste simulacro de tratamento. (Bezerra Júnior, 1997, p.148)

O fato de o CAPS esbarrar nas dificuldades de articulação e burocratização para estabelecer parcerias no egresso de seus usuários, e essa forma de assistência na Atenção Básica desafiam todos esses serviços a elaborarem novas estratégias para lidar com essa nova cronificação. Agora, não mais em decorrência dos anos de aprisionamento nos manicômios, mas dos mecanismos que ainda tornam os usuários altamente dependentes dos serviços por muitos anos.

Aproximar-se dos familiares pode ser uma estratégia para lidar com tal problemática. Essa questão aparece como uma preocupação dos serviços, e configura-se num desafio para viabilização do modelo de atenção à saúde mental com ênfase no convívio social, como destaca P14:

“Temos dois grandes desafios. Primeiro, trabalhar a família em um novo modelo. Trazer a família para dentro do serviço, como co-autora do tratamento, entendendo que ela é parte do tratamento. É um desafio da reabilitação".

Cooper (1989) considera as relações familiares importantes para levarem o sujeito ao adoecimento psíquico, ressaltando a necessidade de atenção dos profissionais a essa questão. Lancetti (2008) e Melman (2001) defendem serem fundamentais intervenções junto à família, como forma de manter o usuário com transtorno mental num convívio familiar e comunitário. Destacam que, se bem apoiada, a família pode ser bastante benéfica ao usuário em tratamento.

Os profissionais relatam que conseguem desenvolver algumas parcerias com os familiares, no tratamento ao usuário. Entretanto, os serviços encontram dificuldades para organizar uma atenção diferenciada às necessidades dos familiares, o que pode gerar diferentes perspectivas e uma exigência por resolução mais imediata por parte dos familiares:

\footnotetext{
"Os familiares demandam resolução imediata, o que não estão de todo errado. Demandam diminuição do sintoma, que é um problema familiar, impede a pessoa de trabalhar, prejudica o sustento. A doença mental é empobrecedora. As intervenções rápidas são a internação e medicação excessiva. Os familiares não entendem isso". (P6)
}

A quase inexistência de articulação intersetorial prejudica a assistência adequada em saúde mental, sendo minimizada quando se trata do CAPS e do CAPSad até 18 anos. O primeiro enfrenta dificuldade para se aproximar de vários serviços, mas, no desafio da reinserção dos usuários no mercado de trabalho, apoia uma cooperativa, em parceria intersetorial com a UFSCar. Já o CAPSad até 18 anos, se mantém próximo à Secretaria de Infância e Juventude, Conselho Tutelar e Judiciário, mas não consegue estabelecer parceria com a universidade para agregar novas ofertas aos usuários por intermédio, por exemplo, de estagiários de educação física.

Profissionais dos dois serviços apontam a necessidade de intervenções extramuro, articuladas com a rede da saúde, com serviços de outras Secretarias, com a gestão de outras Secretarias, ONGs, Judiciário, enfim, com o território no qual se encontram inseridos. Mas justificam que falta recurso humano para viabilizá-las:

\footnotetext{
"Pelo nosso desejo de ação psicossocial, a nossa equipe é muito pequena. Você fazer ação psicossocial demanda profissional, tempo, ele tem que sair e ir para o território". (P14)
}

Amarante (2007) adverte sobre os prejuízos que isso acarreta, pois, quanto menor for o trabalho de base territorial, cada vez mais o profissional será pressionado a atuar no espaço interno do serviço.

Mas não há somente um problema de articulação. Os trabalhadores relatam a inexistência de serviços, como: CAPS III, leitos psiquiátricos em hospital geral, serviços de emergência psiquiátrica e 
CAPSad para maiores de 18 anos. Por não haver esse CAPSad, o acompanhamento mais intensivo, para as pessoas em uso prejudicial de álcool e/ou drogas, é restrito ao hospital psiquiátrico, com grandes chances de reinternação. A falta de um serviço estruturado para atender emergência psiquiátrica prejudica intervenções em situações de crise e a avaliação mais adequada daqueles que precisam de ambiente protegido. O fato de haver uma defasagem no número de profissionais, com prejuízos de oferta, de avaliação e de tempo de tratamento, aumenta as possibilidades de crise e de reinternação. Entre outras consequências, a falta desses serviços provoca um uso aumentado da internação em hospital psiquiátrico, como alternativa terapêutica.

Isso denota a importância do investimento em uma nova organização da assistência, assim como foi feito em Quixadá/CE (Brasil, 2006a; Lancetti, 2001) e Cabo Santo Agostinho/PE (Lancetti, 2001), que reorganizaram os serviços locais de saúde, com funcionamento em rede e ampliação da estrutura de cuidado no próprio município, reduzindo a necessidade de internação e reinternação em outros municípios.

Embora se trate de uma proposta limitada, sem mencionar transformações estruturais, há uma alternativa pensada para assumir mais esse cuidado no município:

\begin{abstract}
"A nossa ideia não é não internar, mas não internar fora. [...] Não queremos contrapor a crise, mas a gente quer que ela seja tratada de uma forma mais humanizada e com mais qualidade. Não é necessária a internação num hospital por meses. Saiu da crise, volta para atendimentos no CAPS. Esse é um ponto. O outro é passar esse CAPS, para CAPS III. Se conseguirmos isso, vai ter alguns leitos aqui. Pelo menos a gente segura a crise, dos usuários do CAPS, aqui mesmo". (P14)
\end{abstract}

Esta afirmação denota uma intenção em assumir o recurso do ambiente protegido no CAPS. Entretanto, denuncia que a noção de serviço substitutivo do CAPS não está plenamente incorporada, na medida em que o profissional se restringe a questionar a carência de humanidade e qualidade da internação em hospital psiquiátrico, não questionando a necessidade ou a função dessa instituição no modelo da Atenção Psicossocial.

Entre tantas queixas e dificuldades apresentadas, até então, há uma questão valorizada: muitos profissionais destacam o bom desempenho dos seus serviços, atribuindo os problemas a algo inerente ao trabalho, como nesta fala:

"Gosto muito [do serviço em que estou inserido]. Têm problemas, sem dúvida nenhuma, porque trabalhar em equipe não é fácil. Às vezes, a gente não concorda e quer fazer do jeito da gente. Acaba, às vezes, desperdiçando energia, cada um fazendo alguma coisa. Mas acho que a tentativa está na unificação. Eu gosto muito de trabalhar nessa equipe". (P1)

Aqueles profissionais mais solitários, alocados na Atenção Básica, falam sobre seus esforços para realizar um bom trabalho e avaliam bem o próprio desempenho.

Vários, ao se referirem às condições de trabalho, apontam: inadequações de espaço físico, baixa remuneração, insuficiência de capacitação e suporte para proporcionar uma condição acolhedora tanto ao usuário quanto ao profissional, exigências por rapidez na resolutividade e tempo reduzido para atendimento. Não se pode, simplesmente, desconsiderar essas queixas sobre o ambiente de trabalho, mas é curioso perceber que este ainda é visualizado dentro dos limites do espaço interno. Ou seja, esses profissionais não consideram, como componentes do seu ambiente de trabalho, o território e as articulações com outros profissionais, serviços e setores.

Sobre a relação dentro de cada serviço, fica evidente que há uma aproximação maior entre os profissionais dos serviços especializados, em comparação com a estabelecida na Atenção Básica, como está explícito nas falas de um profissional de Serviço Especializado, e de um da Atenção Básica, consecutivamente: 


\begin{abstract}
"Gosto muito de trabalhar com o pessoal aqui, não tenho dificuldades. A relação acontece de acordo com a necessidade. A questão assistencial se organiza quase que por si só. Você vai se organizando pelas necessidades". (P6)

"O que eu acho ruim é que a gente trabalha sozinha, não tem equipe no ambulatório". (P9)
\end{abstract}

Desta forma, fica explícito o prejuízo do trabalho multiprofissional na Atenção Básica, onde é pequena a aproximação entre os profissionais de saúde mental e, menor ainda, desses com os demais profissionais. É relatada a falta de espaços para a discussão entre profissionais e de preparo para o trabalho em equipe. Em algumas USFs, essa relação tem se estreitado com o início do apoio matricial dos psiquiatras, que, no mínimo, aproximou o médico de família e o psiquiatra.

Um dos fatores que favorece o isolamento desses profissionais é a própria organização dos NIS, que são serviços de Atenção Básica com atendimento ambulatorial de psicólogo e psiquiatra. A assistência desses trabalhadores caracteriza-se pela descentralização do antigo ambulatório central, sem transformações significativas de suas atuações. Na verdade, trata-se de uma Atenção Especializada, alocada em um serviço de Atenção Básica, sem que se configure uma equipe, com a participação desses profissionais de saúde mental.

De maneira geral, a organização entre serviços de saúde mental segue uma concepção de cuidado fragmentado. Para cada estágio em que se encontra o usuário, há um serviço, e cada um lida com um objeto próprio. Há, portanto, uma política7 que não prevê articulações efetivas e estabelecimento de parcerias.

Embora, em São Carlos, perceba-se um investimento na orientação da Saúde a partir da Atenção Básica, com uma proposta de descentralização dos serviços especializados, incluindo a atenção à saúde mental; constata-se, a partir das entrevistas, que não se trata de uma política formulada e nem discutida em espaços coletivos formais e regulares, com a presença dos trabalhadores. Um deles diz:

\footnotetext{
"Pode ser que exista uma política de saúde mental ou uma estruturação sendo elaborada, mas nunca fui chamado a participar disso". (P10)
}

Apesar de algumas propostas estarem em desenvolvimento no município, grande parte dos profissionais não se sente participante e nem se sente contemplado por elas, motivos que, provavelmente, prejudicam sua implementação e diminuem as chances de se efetivarem.

Os trabalhadores apontam solidão e individualidade em seus cotidianos:

"O sistema de saúde mental ainda está baseado muito nas capacidades individuais. O sistema de saúde não tem nada a oferecer ao profissional que trabalha aqui, a não ser trabalho. Agora, como você vai fazer esse trabalho é problema seu". (P11)

"A gente sente que a gente aqui faz o nosso trabalhinho mesmo, tijolinho por tijolinho do jeito da gente". (P3)

Durante o período das entrevistas, existiu um coordenador de saúde mental, que poderia ter conduzido a discussão da atual política, organizado espaços 
coletivos e oportunizado transformações. No entanto, ele deixou o cargo após menos de um ano de trabalho e a sua atuação mostrou-se muito discreta, conforme relato dos entrevistados. Alguns nem se lembraram da existência dele, outros se referiram a um processo inicial, e outra parte mostrou-se descrente com relação aos alcances dessa figura.

É possível dizer que, até o momento, não tem ocorrido um planejamento feito a contento para a construção dessa política. Segundo Paim (2008), o planejamento, quando feito por meio de construção conjunta e com objetivos e finalidades explicitados, favorece a participação dos trabalhadores na gestão e comprometimento com as decisões tomadas. Para tal, como enfatiza o autor, a sua formulação não pode se resumir ao cumprimento de exigências burocráticas, o que se configuraria em mero comportamento ritualístico.

\section{Considerações finais}

Diante dos relatos dos entrevistados e da observação participante, é possível afirmar que o atual arranjo de serviços no município de São Carlos apresenta avanços, mas ainda insuficientes para dar suporte necessário aos profissionais e atender, adequadamente, aos usuários. Longe do funcionamento, na lógica do cuidado, que prevê boa organização em rede e corresponsabilizações, esse arranjo provavelmente ainda não apresenta boa resolutividade às necessidades de saúde mental do município.

Persistem consequências negativas de um longo período em que o município não se apropriou devidamente do cuidado em saúde mental, entre as quais, um baixo acúmulo de experiência nesta área. Muitas vezes, isto provoca a sensação, em alguns profissionais, de estarem consertando erros do passado, ao invés de realizarem avanços.

A implantação da rede foi, e ainda é, marcada por mudanças internas e estruturais, provocando desestabilidade e divergências importantes entre serviços, profissionais e gestores, o que, em parte, deve-se à não utilização de espaços formais e regulares para planejamento e tomada de decisão.

Este processo e a formulação de uma política de saúde mental ainda se mostram pouco consistentes, na medida em que não há consensos coletivos e as atuações profissionais são pautadas mais por concepções individuais.

O investimento em Educação Permanente pode ser um recurso importante para aproximar esses profissionais, propiciar a construção de espaços coletivos deliberativos e ampliar a qualificação da assistência.

Importante considerar que o processo de transformação não se restringe às ações e definições de gestores. Durante o estudo, percebeu-se uma baixa mobilização dos profissionais, enquanto coletivo, explicada, em parte, pela própria organização dos serviços e baixa formação de parcerias entre profissionais e serviços. Assim, os profissionais se mostraram pouco implicados no processo de transformação de proporção municipal, destinando essa função à gestão. Como consequência, as queixas e tentativas de mudanças acabam sendo localizadas e individualizadas, não provocando discussões e transformações mais amplas.

A ausência de estrutura organizada, para atender determinadas problemáticas, gera complicações e impede que o município assuma a assistência necessária e plena para sua população. Faltam serviços recomendados pelo Ministério da Saúde, considerando a dimensão de São Carlos/SP, como: CAPSad adulto, CAPS III e CAPSi.

Ainda se mostra pequena a articulação entre a Estratégia Saúde da Família e outros dispositivos de saúde mental. Isso contribui para o aumento da medicalização excessiva e a diminuição de ações no território, com as famílias e a comunidade. Amarante (2007), Lancetti e Amarante (2008), Lancetti (2001, 2008), Nunes, Jucá e Valentim (2007) destacam quanto essa articulação é fundamental para se efetivarem as propostas da reforma psiquiátrica.

Essas considerações a respeito do arranjo dos serviços não devem ser entendidas como intenção de burocratizar a assistência, mas apontar a organização estrutural necessária para que, nos diferentes lugares pelo qual passar o usuário, os projetos terapêuticos contemplem a singularidade. 
Nos últimos anos, a aproximação com a universidade, numa proposta de formação da Rede Escola de Cuidado, foi utilizada também como forma de provocar inquietações e mudanças na organização da assistência à saúde. Mesmo estando em processo inicial de estruturação, tem gerado debates e exigido mudanças, o que pode se tornar algo produtivo e transformador.

Existem esforços para a implantação da rede de serviços. No entanto, os dados apresentados impedem a afirmação de que haja um trabalho em rede na saúde mental neste município, configurando-se mais em conjunto de serviços e profissionais de saúde que prestam assistência em saúde mental sem as articulações necessárias. Ainda assim, ressalta-se que vários dos aspectos apresentados, neste estudo, repetem-se em outros contextos, mesmo naqueles que apresentam maiores avanços. Espera-se que os apontamentos realizados contribuam para a reavaliação dos caminhos adotados pelo município; e para que profissionais, gestores e usuários de outras localidades possam se beneficiar da discussão apresentada e refletir sobre o seu próprio território, gerando potenciais de transformação.

\section{Colaboradores}

Daniel Vannucci Dobies foi responsável pela elaboração, planejamento e execução da pesquisa e redação do artigo. Luciana Nogueira Fioroni orientou a elaboração e desenvolvimento da pesquisa e redação do artigo.

\section{Referências}

AMARANTE, P. Saúde mental e atenção psicossocial. Rio de Janeiro: Fiocruz, 2007. (Temas em Saúde)

Asilos, alienados e alienista: pequena história da psiquiatria no Brasil. In: $\overline{\text { p.73-84 }}$

(Org.). Psiquiatria social e reforma psiquiátrica. Rio de Janeiro: Fiocruz, 1994.

BASAGLIA, F. A instituição negada: relato de um hospital psiquiátrico. Rio de Janeiro: Graal, 1985. (Biblioteca de Filosofia e História das Ciências, n.17)

BEZERRA JR., B. Considerações sobre terapêuticas ambulatoriais em saúde mental. In: TUNDIS, S.A.; COSTA, N.R. (Orgs.). Cidadania e loucura: políticas de saúde mental no Brasil. 5.ed. Petrópolis: Vozes, 1997. p.133-69. (Coleção Saúde e Realidade)

BRASIL. Ministério da Saúde. Política Nacional de Saúde Mental. Disponível em: $<$ http://portal.saude.gov.br/portal/saude/visualizar_texto.cfm?idtxt=24134>. Acesso em: 5 mar. 2009a.

Saúde Mental passo a passo: como organizar a rede de saúde mental no seu município? Disponível em: <http://portal.saude.gov.br/portal/arquivos/pdf/ rede_de_saude_mental_revisado_6_11_2008.pdf>. Acesso em: 5 mar. 2009b.

Secretaria de Atenção à Saúde, Política Nacional de Humanização. Boas Práticas de Humanização na Atenção e na Gestão do Sistema Único de Saúde. O Centro de Atenção Psicossocial de Quixadá: uma política cidadã de saúde mental. Brasília, 2006a.

Secretaria de Atenção à Saúde, Política Nacional de Humanização. Boas Práticas de Humanização na Atenção e na Gestão do Sistema Único de Saúde. Política de Saúde Mental de Belo Horizonte. Brasília, 2006b. 
CASTEL, R. A instituição psiquiátrica em questão. In: FIGUEIRA, S.A. (Org.). Sociedade e doença mental. Rio de Janeiro: Editora Campus, 1978. p.149-93.

COOPER, D. Psiquiatria e antipsiquiatria. São Paulo: Perspectiva, 1989. (Coleção Debates, v.76)

FOUCAULT, M. Doença mental e psicologia. 2.ed. Rio de Janeiro: Tempo Brasileiro, 1984. (Biblioteca Tempo Universitário, 11).

HARARI, A.; VALENTINI, W. (Orgs.). A reforma psiquiátrica no cotidiano. São Paulo: Hucitec, 2001. (Saúdeloucura, 14).

KODA, M.Y.; FERNANDES, M.I.A. A reforma psiquiátrica e a constituição de práticas substitutivas em saúde mental: uma leitura institucional sobre a experiência de um núcleo de atenção psicossocial. Cad. Saude Publica, v.23, n.6, p.1455-61, 2007.

LANCETTI, A. Clínica peripatética. São Paulo: Hucitec, 2008. (Saúdeloucura, 20. Série Políticas do Desejo, 1)

(Org.). Saúde mental e saúde da família. São Paulo: Hucitec, 2001. (Saúdeloucura, 7).

LANCETTI, A.; AMARANTE, P. Saúde mental e saúde coletiva. In: CAMPOS, G.W.S. et al. (Orgs.). Tratado de saúde coletiva. 2.ed. São Paulo: Hucitec, 2008. p.615-34. (Saúde em Debate, v.170).

MATTOS, R.A. Repensando a organização da rede de serviços de saúde a partir do princípio da integralidade. In: PINHEIRO, R.; MATTOS, R.A. (Orgs.). Razões públicas para a integralidade em saúde: o cuidado como valor. Rio de Janeiro: Cepesc, IMS/ UERJ, Abrasco, 2007. p.369-83.

MELMAN, J. Família e doença mental: repensando a relação entre profissionais de saúde e familiares. São Paulo: Escrituras, 2001. (Coleção Ensaios Transversais).

MERHY, E.E.; AMARAL, H. (Orgs.). A reforma psiquiátrica no cotidiano II. São Paulo: Hucitec, 2007. (Saúdeloucura, 22)

MINAYO, M.C.S. O desafio do conhecimento: pesquisa qualitativa em saúde. 7.ed. São Paulo: Hucitec, 2000.

NUNES, M.; JUCÁ, V.J.; VALENTIM, C.P.B. Ações de saúde mental no Programa Saúde da Família: confluências e dissonâncias das práticas com os princípios das reformas psiquiátrica e sanitária. Cad. Saude Publica, v.2, n.10, p.2375-84, 2007.

OMS. Informe sobre la salud en el mundo 2001: salud mental - nuevos conocimientos, nuevas esperanzas. Ginebra: OMS, 2001.

PAIM, J.S. Planejamento em saúde para não especialistas. In: CAMPOS, G.W.S. et al. (Orgs.). Tratado de saúde coletiva. 2.ed. São Paulo: Hucitec, 2008. p.767-82 (Saúde em Debate, v.170).

RESENDE, H. Política de saúde mental no Brasil: uma visão histórica. In: TUNDIS, S.A.; COSTA, N.R. (Org.). Cidadania e loucura: políticas de saúde mental no Brasil. 5.ed. Petrópolis: Vozes, 1997. p.15-73 (Coleção Saúde e Realidade Brasileira).

SÃO CARLOS. Prefeitura Municipal de São Carlos. Disponível em: <http:// www.saocarlos.sp.gov.br>. Acesso em: 5 out. 2007.

SPINK, M.J.P. et al. A inserção de psicólogos em serviços de saúde vinculados ao SUS: subsídios para entender os dilemas da prática e os desafios da formação profissional. In: SPINK, M.J.P. (Org.). A psicologia em diálogo com o SUS: prática profissional e produção acadêmica. São Paulo: Casa do Psicólogo, 2007. p.53-80.

TENÓRIO, F. A reforma psiquiátrica brasileira, da década de 1980 aos dias atuais: história e conceitos. Historia, Cienc. Saude - Manguinhos, v.9, n.1, p.25-59, 2002. 
DOBIES, D.V.; FIORONI, L.N.

DOBIES, D.V.; FIORONI, L.N. La asistencia en salud mental en el municipio de São Carlos, estado de São Paulo, Brasil: consideraciones sobre la historia y la actualidad. Interface - Comunic., Saude, Educ., v.14, n.33, p.285-99, abr./jun. 2010.

La actual política de la salud mental atribuye importancia a la red de servicios para atender a las personas con transtorno mental en relación con la comunidad, con el respaldo del apoyo técnico y social. Se ha realizado un estudio con el objetivo de investigar, describir y prantear la política de salud mental en el municipio de São Carlos a partir de los servicios y acciones en salud mental, utilizando entrevistas semiestructuradas con profesionales y observación participante. Se observa un atraso histórico en el cuidado con la salud mental; los servicios son recientes, demandando mejoras o transformaciones y la red de salud exhibe fragilidades. El arreglo actual presenta avances todavía insuficientes para dar soporte a los profesionales y atender a los usuarios. Se torna necesaria la construcción colectiva de una política de la salud mental con participación más activa de los profesionales y la inversión en educación permanente. La aproximación con la universidad podrá contribuir en este proceso.

Palabras clave: Red de la salud mental. Política de la salud mental. Atención psicosocial. Atención en salud mental.

Recebido em 31/03/09. Aprovado em 26/10/09 